\title{
The Role of Participatory Environmental Monitoring Committees in Mining Regions in Peru
}

\author{
Andre Xavier ${ }^{*}$, Aldo Leon ${ }^{1}$, Alexandra Carlier ${ }^{2}$, Manuel Bernales ${ }^{3}$ and Bern Klein ${ }^{1}$ \\ ${ }^{1}$ Canadian International Resources and Development Institute (CIRDI) and Norman B. Keevil Institute of Mining \\ Engineering at the University of British Columbia (UBC) \\ ${ }^{2}$ Pontificia Universidad Católica de Peru (PUCP) and Canadian International Resources and Development Institute (CIRDI) \\ ${ }^{3}$ Futuro Sostenible
}

\begin{abstract}
Mining companies and governments at both the local and national levels recognize that Participatory Environmental Monitoring and Surveillance Committees (PEMSC) are necessary mechanisms for meaningful engagement at the community level. In many cases, PEMSCs are established as volunteer initiatives by mining companies or by the mining communities themselves. In Peru however, they can also be recommended by the government as way to address social conflict. Most PEMSCs are launched while a mine is in operation and have the objective of monitoring both water quality and quantity. Many established committees are currently evolving and adopting a more comprehensive approach, as well as expanding their initial scope from a river or micro-basin focus and watchdog agenda, to a broader regional integrated resources management view. This paper examines the origins of Participatory Environmental Monitoring and Surveillance Committees in Peru. It also discusses the typology of these committees, and the scope of their work. Furthermore, it looks at the challenges faced by these committees, as well as existing opportunities for mining companies, governments, and civil society. Finally, this study presents a governance model that could contribute to the long-term existence of these committees. This discussion is further informed by the results of a national workshop that took place in October 2016 in Peru, in which over 200 representatives from 22 monitoring committees, government and mining companies participated.
\end{abstract}

Keywords: participatory environmental committees, trust, community engagement, integrated water resources management

\section{Introduction}

The extractive industry in Peru represents a significant economic contribution to the country. Specifically, mining activity generates approximately $60 \%$ of total exports and contributes $14.5 \%$ to the Gross Domestic Product (GDP). Furthermore, the national government and subnational governments benefit from mining tax revenues and royalties. In 2015, approximately US\$ $880^{1}$ million were transferred under this concept (Ministerio de Energía y Minas 2016a). In November 2016, the estimated investment portfolio ${ }^{2}$ in mining projects was US\$ 46 billion (Ministerio de Energía y Minas 2016a).

Another type of contribution made by the mining industry is that of social responsibility programs that are supported by the companies. For example, in 2014,

\footnotetext{
${ }^{1}$ Equivalent to approximately 2.9 billion PEN.

${ }^{2}$ Amount reported by the Ministry of Energy and Mines (MINEM, by its Spanish initials). Takes 45 major projects into account including mining unit extension projects, projects at the advanced exploratory stage and projects whose Environmental Impact Assessment has been approved, or is under evaluation.
}

US\$ 205 million were invested in the development of social projects (Ministerio de Energía y Minas 2016b).

Despite the role and importance of mining activity to the Peruvian economy, opposition to mining projects has increased. In particular, the concerns of local populations related to environmental impacts have led to social conflict. Even though, in the Peruvian case, water consumption in mining accounts for only $1.5 \%$ of Peru's water, public perception is that mining activities pollute water sources and limit water availability for both agriculture and human consumption (Instituto Nacional de Estadística e Informática 2014). Furthermore, it is held that the main sources of protests and complaints involve beliefs about the negative effects of mining activities on water sources (Rojas 2010). The Tía Maria project in Arequipa, and the Conga project in Cajamarca, Peru are recent examples of cases in which, due to concerns related to water quality and quantity, farmers, local citizens and local authorities have turned against the projects.

In October 2016, the Ombudsman's Office reported 149 active social conflicts, 97 of which involved communities and mining companies (Defensoria del Pueblo 2016). With respect to social conflicts around the issue of water, from January 2011 to December 2014, the Ombudsman's Office reported 153 social conflicts, $75 \%$ of

* Corresponding Author: A. Xavier, andre.xavier@ cirdi.ca, phone: +1 604-822-2540

Copyright @ 2017 Canamaple Academia Services, http://press.camdemia.ca

DOI: 10.15273/gree.2017.02.032 
which were reported in rural areas where the main complainants were from local peasant communities. In various conflicts related to issues concerning water quality and quantity, round-tables facilitated by the government were set up, resulting in the recommendation to create Participatory Environmental Monitoring and Surveillance Committees (PEMSC) as part of the action plan for addressing these conflicts. The Supreme Decree \# 0202008-EM, through the Regulations of Citizen Participation in the Mining Industry determines that once a mining company has received approval on its project's Environmental Impact Assessment (EIA), the company should engage in participatory monitoring activities.

In recent years, PEMSCs have allowed for local communities to play a more active role in understanding the situation with respect to water resources in their communities. Furthermore, PEMSCs have encouraged the participation of local communities and authorities, thus reducing distrust and addressing concerns about impacts related to mining activities (Lopez 2009). Moreover, working through PEMSCs can help reduce and avoid conflicts related to water in the extractive industry (Oficina del Asesor en Cumplimiento/Ombudsman 2008). Some mining companies have implemented PEMSCs, and in some cases, non-governmental organizations have provided financial and technical assistance for community-driven PEMSCs (Villalobos 2013). However, one of the main opportunities provided by such initiatives is that they help improve the level of citizen participation in the development of mining projects.

\section{Drivers for the Establishment of PEMSCs}

PEMSCs can be considered as coordination entities that promote multi-stakeholder engagement through which civil society, mining companies and different levels of government come together to discuss environmental issues, and particularly those related to water resources. The stages for the creation of a monitoring committee vary depending on the members involved and the context in which the committee has been generated (Lopez 2009). Four different drivers have been identified as reasons for the establishment of PEMSCs. Participatory Environmental Monitoring and Surveillance Committees are created:

In response to socio-environmental conflicts: in many cases where there are socio-environmental conflicts, the authorities propose the establishment of dialogue roundtables as part of the agreements reached between the parties (government, company and local community). Participatory monitoring committees are set up to address the concerns of the local population regarding potential environmental impacts.

As an initiative of the local communities: in some cases, the communities impacted by the area of influence of a mining project require the establishment of a PEMSC to address questions and concerns with respect to potential environmental impacts derived from the development of mining projects.

As a mining company initiative: In most cases, the establishment of these committees is intended to comply with the Regulations on Citizen Participation in the Mining Industry (Decree \# 020-2008-EM). With respect to this type of initiative, it is common that the mining company takes a leading role in coordinating the activities of the committee. Other initiatives taken by the mining companies to implement PEMSCs involve responding to the need to increase levels of transparency and access to information regarding the development of the mining activities so as to build trust and credibility in the eyes of local stakeholders.

At the initiative of government authorities: some participatory monitoring actions can be set up through the initiative of authorities with environmental competence such as the National Water Authority (ANA) and the Environmental Evaluation and Enforcement Agency $(\mathrm{OEFA})^{3}$. Such cases are usually in response to contexts in which concerns or claims have been made by the local population regarding the potential environmental impact of human activity.

Bilateral agreements between companies and local communities, sometimes defined as Participation Agreements (PA) or Community Development Agreements (CDA), are also spaces that trigger the creation of PEMSCs since these committees are understood to contribute to sustainable development at the local level.

It is fair to say that PEMSCs arise as a result of preexisting concerns about the future of ecosystems and the impacts that mining activities have on natural resources, which could thereby increase the environmental and social vulnerability of local communities.

Representation in these committees can include representatives from among the local communities, local authorities, the national government and mining companies. In some cases, NGO's, university representatives, water users, among others, also participate.

\section{National Meetings on PEMSC}

In response to these participatory monitoring initiatives, in October 2008, and with the participation of some civil society organizations, the Ministry of Energy and Mines (MEM) and some mining companies, the 1st National Meeting of PEMSC — entitled "El Agua nos Reúne" ("Water brings us together") — was held in Lima. Participants included leaders representing communities from 14 regions of Peru, public sector representatives, NGOs, mining companies and universities. A second meeting, entitled "National Workshop on Participatory Environmental Monitoring and Surveillance Committees" was held in November 2012 at the initiative of monitoring committees from Cajamarca, with the support of NGOs and international cooperation agencies. There were approximately 100 participants who represented monitoring

\footnotetext{
${ }^{3}$ Autoridad Nacional del Agua (ANA) and Organismo de Evaluación y Fiscalización Ambiental (OEFA)
} 
committees, government bodies (ANA, OEFA, MINAM ${ }^{4}$ ) and mining companies.

In both events, the participants shared their experiences, achievements and the challenges encountered by various PEMSCs, and produced recommendations aimed at strengthening the role of the aforementioned committees in order to improve the process of citizen participation in the mining sector; improve the management of natural resources; and with the intention of establishing a national network and umbrella organization for the PEMSCs.

\section{Third National Workshop on Participatory Environmental Monitoring and Surveillance Committees - Results, Challenges and Opportunities}

The third national workshop of the Participatory Environmental Monitoring Committees in Mining was carried out on the $25^{\text {th }}$ and $26^{\text {th }}$ of October 2016 in the city of Lima. This event was sponsored by the Canadian International Resources and Development Institute (CIRDI) ${ }^{5}$ and the United Nations Development Program (UNDP), and brought together over 200 representatives from different committees, organizations of the Peruvian government, mining companies, civil society and other institutions (Figure 1). Seventy participants were members of participatory monitoring committees, representing 22 committees from 7 Peruvian regions. Other local organizations including the National Water Authority (ANA), the NGO "Grupo de Diálogo Minería y Desarrollo Sostenible" (GDMDS) ${ }^{6}$ and Futuro Sostenible, Tinkuy Consulting, and the Federation of Canadian Municipalities also assisted in the organization of the event. The main goal of the workshop was to create an opportunity to exchange experiences and reflect on roles, strengths, achievements, weaknesses and results; and to identify opportunities for continuity and strengthening the role of the PEMSCs in the mining sector.

\section{Workshop Participants}

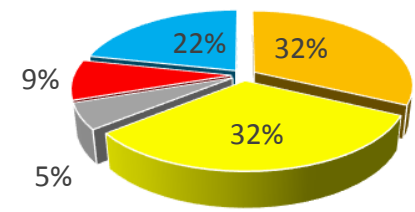

- Committees

Civil society organizations \& authorities

- Mining companies Mineras

Figure 1 Attendees by affiliation.

\footnotetext{
${ }^{4}$ Ministry of Environment

${ }^{5}$ www.cirdi.ca

${ }^{6}$ Dialogue Group in Mining and Sustainable Development
}

Despite the fact that similar events have taken place in the past, it was reported by the participants that this was the first time in recent years that the different government organizations came together to reflect on the role and importance of PEMSCs. During the panel where all participants represented the government, it was concluded that more integration and coordination between government bodies would be useful.

Either to comply with regulations or as a way of creating an opportunity for community engagement, mining companies are taking the lead in supporting the establishment of Participatory Environmental Monitoring and Surveillance Committees.

During the two day of event, several topics were discussed, and they generated valuable information including with respect to challenges and opportunities. These are summarized in the following paragraphs.

\subsection{Establishment and organization of participatory environmental monitoring and surveillance committees sub heading of your paper}

- The need to promote continuous financial and logistical support for PEMSCs was emphasized as means towards contributing to their long-term existence so that they can subsist and continue to play their environmental roles.

- PESMCs should be viewed as mechanisms of an early environmental warning system (facilitating early governmental intervention) and not as (re)actions in response to the concerns of the population.

- In order to gain further support from the population, PESMCs need to be formalized and registered organizations.

- Emphasis should be placed on implementing training processes prior to the creation of a PEMSC. Training could be delivered in partnership with regional universities.

- An accurate inventory of PEMSCs is required; according to current participants, it is not known how many such committees are functioning in Peru.

- PESMCs are seen as a mechanism through which to promote public participation, and as a tool that encourages dialogue and trust-building among distinct parties. Furthermore, they can assist in resolving socioenvironmental conflicts.

\subsection{Developing and maintaining PEMSCs' institutional strength}

- Some government representatives perceive that PESMCs do not enjoy the full trust of local communities, which sometimes view these committees as being aligned with the mining sector, or even with the government, especially when the lab analysis of water samples results do not show any negative impacts.

- Committee members consider that a legal framework that recognizes, formalizes and regulates the existence of the committees is required. Through this measure, mechanisms could be defined and regulated so as to finance operations and to provide technical training to 
committee members. Committee members perceive that through obtaining increased government support, higher levels of social trust can be put in the committees, since they would depend less on resources allocated by the mining sector.

- Recommendations were made that a portion of the mining taxes that are returned to the regions in the form of the Canon Minero ${ }^{7}$ should be allocated to fund the operations of the committees.

- The institutional strength of the committees, and being perceived as independent were also topics of concern to participants who claimed that when mining companies finance these committees, it is deleterious to trust building.

- Government, NGOs and universities each have a role to play in providing guidance and technical support so that the committees can be properly equipped with the core knowledge necessary for the implementation of their activities.

- The high turnover of members of the PEMSC is seen as a challenge that must be dealt with in order to support the longevity of the committees.

\subsection{Community environmental monitoring and surveillance}

- Participatory environmental monitoring efforts aim towards collecting information about water quality, which can guide the citizens and the government with respect to the actions needed to protect and sustain this resource.

- Although it was recognized that, when conducting monitoring efforts, the main focus is on water quality, it should be emphasized that it is necessary to consider both water quality and quantity.

- In addition to having a financial mechanism in place to support PEMSC operations, establishing annual plans, training, and education programs for the committee members is fundamental to ensuring that PEMSCs are sustainable and that they improve their performance.

- Learning and collaboration among PEMSCs should take place, and the establishment of a collaborative network of PEMSCs would be valuable.

- Local universities have a role to play in conducting research and in supporting and developing the technical and governance capacity of the committees.

\section{Challenges Associated with PEMSCs}

Although the implementation of PEMSCs in the Peruvian mining context was initiated more than a decade ago, as noted during the $3^{\text {rd }}$ workshop, there continue to be many challenges associated with the functioning of PEMSCs.

\footnotetext{
${ }^{7}$ With the aim of promoting economic growth and development in the mining regions, in the Peruvian case, $50 \%$ of the mining companies' income taxes are redistributed to the regions under the concept of Canon Minero. For instance, municipalities in the province where mining operations take place equally share $25 \%$ of the Canon. In turn, districts where the operations are located receive $10 \%$ of the Canon funds.
}

Some of these challenges relates to:

- Funding - Lack of financial resources prevents committee members from developing their technical capacity, and it also has negative impacts on monitoring activities and on the payment of expenses associated with PEMSC activities such as the costs of certified laboratory analysis. Although lack of funding can be problematic, the source of funding, and how it is managed can also be a source of concern. In cases where mining companies directly finance the activities of the monitoring committees, the credibility of the committees and the information that they produce, can be questioned, as other community members may be suspicious that results are skewed towards the interests of the mining company;

- Institutional recognition - Although the Peruvian regulation on citizen participation (D.S. \#028-2008-EM article 5, clause 5.5) refers to citizen oversight, stating that "communities of interest around mining projects have the right to monitor, control and follow up on the measures, actions, obligations and commitments adopted by the mining companies with respect to the environmental and social aspects related to the mining activity," according to the current regulations, there are no guidelines in place to support institutional recognition or the legal status of these committees. Lack of institutional recognition limits the authority of these committees and perpetuates power imbalances. Legally-constituted organizations provide a durable institutional structure that can allow members to work together on long-term goals. They can empower the community and support the development of trust and respect between and among the community, government and the mining company;

- Social legitimacy - Some committee members have received financial compensation from mining companies, resulting in an overall lack of trust from the community. On the other hand, due to a generalized lack of trust in government authorities, government participation in the committees can also result in lack of trust;

- Participation - another factor that has challenged the efforts of PEMSC committees is lack of participation. Monitoring activities can take up to two days to complete since access to the monitoring points is not always easy or straightforward. Considering that most PEMSCs are volunteer-based organizations, and that many committee members would lose income to participate in monitoring activities, this therefore discourages community participation. Lack of funding is also another limiting factor for community participation.

\section{Integrated Governance Model for PEMSCs}

To maximize opportunities and address some of the challenges outlined in the previous sections, the Peruvian NGO Futuro Sostenible is developing a conceptual integrated model for the participatory monitoring committees. This model seeks to develop processes and standards to put in place to contribute to the success of these committees. 


\subsection{Governance and institutional strength of the committees}

The communities democratically elect representatives to their assemblies, and these representatives also function as members of the committee. To this end, committees require processes and tools to create and maintain the transparency of their activities. Committees need to develop norms, protocols and procedures for the participation of their members. An annual plan that includes a monitoring schedule as well as a communication plan is a key document.

\subsection{Development of technical, leadership and interpersonal skills, and continuous learning}

Committee members need to develop fundamental knowledge about environmental science, and the necessary technical skills to conduct environmental monitoring. This needs to involve a continuous process of learning that would eventually allow committee members to be able to answer various questions about potential environmental impacts. The process of data analysis and its interpretation are important elements of this learning process. An Integrated Resource Management approach with a strong focus on water and waste can be adopted to guide the education and training processes. Furthermore, the development of communication and leadership skills are also required so that members can inform and advise their communities regarding environmental issues of concern.

\subsection{Environmental surveillance and monitoring}

In partnership with the mining company, committee members participate in monitoring activities, and involve national and local authorities. The results are analyzed as a whole with the aim of making decisions that will ultimately improve the company's environmental performance and protect the environment. At the same time, the knowledge that the community has developed helps improve the design of environmental monitoring systems.

Successful committees improve their scope over time. In this context, Rio Tinto's La Granja Project is an interesting case. The project is still in the exploration phase but the company voluntarily decided to support the creation of Participatory Environmental Monitoring and Surveillance Committees as a way of responding to its communities' concerns regarding the potential impacts of its activities on local water bodies. Over time, in addition to continuing environmental monitoring activities, these committees began to take a more comprehensive view of their environment. They initiated composting, orchards and reforestation projects, and began to identify strategies through which to solve the severe problem of waste disposal in their communities. They have also constituted a working group that takes a regional and integrated look at the water users in the area.

\section{Conclusions and Recommendations}

In the Peruvian context, Participatory Environmental Monitoring and Surveillance Committees have been in operation for many years. They were initially created because of the environmental concerns of local populations, and their existence is supported by a law that requires mining companies to engage in participatory processes to monitor environmental issues.

Water is a very contentious topic in Peru, and many of the previous, as well as current conflicts are related to water issues. This helps explain why the existing PEMSCs focus on water monitoring.

Participants in the third national workshop of the Participatory Environmental Monitoring Committees in Mining agreed in general that PEMSCs play an important role in facilitating multi-stakeholder dialogue, and that they contribute to conflict prevention and management. However, to build trust and legitimacy at the local level, they proposed that the role of the committees should be incorporated into the national socio-environmental management policy.

Despite their positive contributions, these committees are facing challenges that hinder their performance. Some of these challenges include lack of technical capacity, unstable sources of funding to support operational costs, and lack of institutional recognition by the government and the society.

The PEMSCs represent an opportunity to strengthen the presence of the government in areas and territories where the government is not currently present. These committees could be seen an extension of the government, since they could function as the first point from which insight and information are shared about the environmental situation.

The establishment of a PEMSC can also be seen as an opportunity to contribute to empowering local populations, leading to the creation of environmental awareness and the establishment of an integrated approach to environmental management at the local level.

The authors believe that a certification system that would function towards improving the good governance of the committees, as well as building their members' technical, leadership and interpersonal skills needs to be put in place to support the long-term survival and contribution of these committees. Such a certification would ensure that high level standards and management protocols are put in place, and that the committee members have the technical competency to conduct the activities of the committee.

\section{References}

Villalobos, E., (editor) 2013. Taller national de comités de monitoreo y vigilancia ambiental participativos memoria, Cajamarca, Peru.

Defensoria del Pueblo, 2016. Defensoria del pueblo. http://www.defensoria.gob.pe/conflictossociales/home.php.

Lopez, J., 2009. Comités de monitoreo y vigilancia ambiental participativos: Recomendaciones para una minería moderna y responsible. www.grupodedialogo.org.pe/monitoreoyvigilanciaambi ental.

Instituto Nacional de Estadística e Informática, 2014. Perú: Anuario de estadísticas ambientales 2013. www.inei.gob.pe. 
Ministerio de Energía y Minas, 2016a. MEM. http://www.minem.gob.pe/minem/archivos/file/Mineria /INVERSION/2016/CARTERA10-2016.pdf.

Ministerio de Energía y Minas, 2016b. MEM. http://www.minem.gob.pe/minem/archivos/file/Mineria /PUBLICACIONES/VARIABLES/2016/NOVIEMBR E.pdf.

Oficina del Asesor en Cumplimiento/Ombudsman, 2008. Monitoreo participativo del agua guía para prevenir y manejar el Conflicto. Oficina del Asesor en Cumplimiento/Ombudsman (CAO) IFC, Washintong, DC, US.

Rojas, S., 2010. La gestión del agua en cuencas con minería: limitaciones desde la sostenibilidad ambiental y la equidad social en la Cuenca Porcón, Perú. http://www.yorku.ca/cerlac/ROJAS.pdf. 